\title{
Parameters of sagittal balance in view of studies on patients suffering from rheumatoid arthritis with cervical spine instability
}

\author{
Robert Wróblewski ID , Robert Gasik ID \\ Neuroorthopaedics and Neurology Clinic and Polyclinic, National Institute of Geriatrics, Rheumatology, and Rehabilitation, \\ Warsaw, Poland
}

\begin{abstract}
Rheumatoid arthritis (RA) is a systemic inflammation, with cervical spine instability being one of the consequences. The instability may lead to myelopathy and even death of the patient due to compression on the spinal vessels and nerve structures of the cervical section. Sagittal balance is one of the issues that has recently contributed to deepening the understanding of spine pathology. As regards RA, sagittal balance is of particular importance due to the nature of the disease, which naturally leads to damage in the physiological joints stabilisers. Joints damaged in the course of the disease become particularly vulnerable to biomechanical balance disorders. Managing patients suffering from RA with cervical spine instability is a serious issue. The literature pays little attention to the sagittal balance in patients suffering from RA. The goal of this paper is to draw attention to the selected parameters of sagittal balance and their mutual relations, as regards cervical spine.
\end{abstract}

Key words: rheumatoid arthritis, cervical spine instability, sagittal balance of the spine.

\section{Introduction}

Rheumatoid arthritis (RA) is a chronic autoimmune inflammatory disease, with cervical spine instability being one of its consequences. Joints in the cervical section of the spine, according to the literature, are the third to be involved by the disease, after joints of the hands and feet [1].

According to Garrod, who in 1890 was the first to describe the involvement of the joints of the cervical spine, they are present in approx. 35\% of the patients; according to our data, radiological changes are observed in over $80 \%$ of the patients [2, 3].

Inflammation in RA leads to the damage of articular cartilages, compact bone erosion, and weakened ligaments, being a great environment for biomechanical balance disorders in joints at different levels of the spine [1]. The course of the destruction process in the joints may be asymptomatic or manifesting with strong pain. Neurological disorders are present in $7-35 \%$ of the patients [2].

In extreme cases, cervical spine instability leads to death as a result of spinal cord compression $[4,5]$. Treat- ing patients with cervical spine instability and accompanying low quality of bones is a serious issue. Sagittal balance is one of the issues that has recently contributed to deepening the understanding of spine pathology [6].

It has been observed that sagittal balance correlates to the quality of patients' lives and is a prognostic factor as regards the effects of surgical procedures [7, 8]. The application of sagittal balance principles in daily surgical practice has significantly improved management outcomes as regards patients suffering from ailments in the lumbar and thoracic spine $[9,10]$.

Fewer papers have so far been published on the understanding and application of sagittal balance in the pathology of the cervical spine [11, 12]. Few publications concern the topic of sagittal balance in patients with instability in the course of RA [13].

The goal of the paper is to draw the attention to selected parameters of the sagittal balance and their mutual relations, as regards cervical spine, as well as to provide diagnostic and therapeutic guidelines to rheumatologists and orthopaedists dealing in everyday practice with patients suffering from RA. 


\section{Cervical spine instability in rheumatoid arthritis}

The joints of the cervical spine are rich in synovial membrane and are predisposed to the development of inflammatory changes in the course of RA. The anatomy, particularly of the upper cervical spine, is characterised by large mobility and no natural osseous stabilisation [14].

As a result of inflammation and mechanical factors, the complex connective tissue system loses its stability. Among other things, the transverse ligament of the atlas, while losing strength, causes widening of the atlantodens interval (ADI). Atlanto-axial subluxation (AAS) is then created. Damage to the conoid ligaments deepens the AAS, resulting in the atlas slipping downwards and to the front, thus decreasing the posterior atlas and dens interval (PADI). The apex of dens penetrates to the foramen magnum (cranial settling - $\mathrm{CrS}$ ).

Within the subaxial area $\mathrm{C2}-\mathrm{C7}$, excessive dislocation of the bodies towards each other and instability of subaxial subluxation (SAS) results both from the destruction of articular surfaces of the adjoining bodies, weakened ligaments between the spinous processes, and destruction of the intervertebral discs connecting the adjoining bodies.

Atlanto-axial subluxation is present in $65 \%$ of the patients with RA, $75 \%$ of all the AAS being anterior subluxations (approx. $75 \%$ of all the AAS); posterior and lateral ones are not as common. Subluxations in C3 through C7 vertebrae (SAS) are described in approx. $20 \%$, while axial dens herniation to the foramen magnum $\mathrm{CrS}$ are seen in approx. $15 \%$ of the cases in patients with RA [12, 14, 15].
Inflammation in RA may cause erosion of the axial dens and its fracture [16].

Lack of connective tissue protection at the above levels may lead to compression on the nerve structures, but also the vessels, leading, e.g., to cerebral thrombosis. Diagnostic imaging in the majority of patients with RA, also without any clinical signs of instability, comprises $X$-ray of the cervical spine AP and lateral, classical and functional. Assessments make it possible to evaluate the structure of the bones and mutual relations. In the case of neurological changes, even in the case of lack of irregularities upon X-ray, it is necessary to have magnetic resonance imaging or computed tomography carried out (Fig. 1).

Regional radiological classifications were drawn up specifying the range of standards and degrees of instability based on the assessments of healthy subjects and ill ones. In cranial settling assessment they are Ranawat classification, Redlund-Johnell criterion, Clark classification, ADI, PADI in AAS value assessment, or assessment of the rate of body displacement and the assessment of vertebral canal diameter in SAS [14, 15].

Classifications applied in the clinical evaluation of myelopathy in RA comprise the Ranawat classification [17] and the classification of the American College of Rheumatology assessing the general functional condition of the patient suffering from RA [3].

It is worth emphasising the fact that neurological clinical signs proving the compression of nerve structures may create interpretation difficulties due to the occurrence in the natural course of RA of limitation in the range of motion, contractures, and weakened muscles.
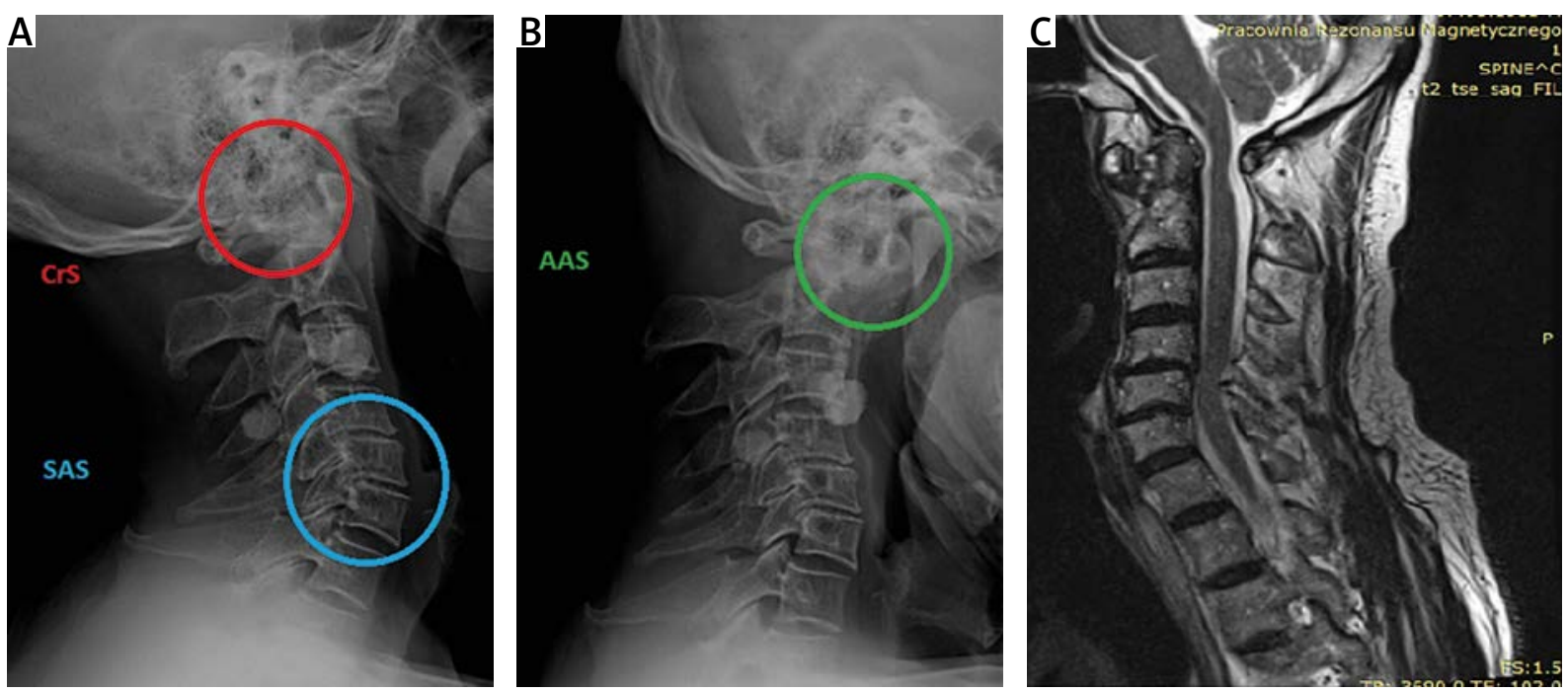

Fig. 1. Lateral X-ray of the neck of a 67-year-old patient with rheumatoid arthritis and instability of cranial settling, atlanto-axial subluxation, subaxial subluxation (A), X-ray of the patient's neck in anteversion (B), magnetic resonance imaging of the neck of the patient made before the planned surgery $(C)$. 


\section{The notion of an efficiency conus, kinematic chain and global sagittal balance}

Dubousset is among the leaders of studies on sagittal balance [18]. According to Dubousset, sagittal balance is a balanced ratio of all the curvatures of the spine (kyphosis, lordosis), which is aimed at keeping the position of the body in space against gravity and economically using as little energy as possible. The position of the body has to simultaneously maintain, as well as the balance, the location of the skull, which enables optimum horizontal field of view $[18,19]$.

A human body is compared to a chain of kinematic constituents, which are affected by equilibrant forces and moments of force [20]. It begins with the support polygon of the feet, later continuing into the ankle joints, knee joints, hip joints, and pelvic girdle, and then through spinal segments to the cervical section and the head. The axes for muscle operation are joints, which in the case of destruction hinder the action of equilibrant forces.

According to the principles of Dubousset's theory, sagittal alignment of the spinal curvatures must be included in the "efficiency conus" [18]. Global sagittal balance is the condition where the location the skull, spine, pelvis, and lower limbs is consistent in order to have an ergonomic posture. This translates into the course of the body line of gravity, the projection of which should be included in the support polygon of the feet.

An optimum course of the line of gravity is the course from the centre of gravity of the head, through the centre of the C2 body, C7 body, femoral head, and through extension of the knee joints to the base area specified by the location of the feet. Such a course of the line of gravity is not common in patients with an advanced RA. Deviations from the optimum condition result in the activation of compensation mechanisms at various levels of the kinematic chain, using up additional energy [21, 22].

Imaging devices coupled with a movement platform are used for specialist assessment concerning body balance in space [23]. However, in everyday clinical practice, the evaluation of sagittal balance parameters translates into static X-rays [24]. The radiological parameters of the evaluation are as follows:

- projections of centre of gravity points of the selected parts of body on the surface area of the support polygon of the feet (vertical sagittal lines),

- geometry and spatial orientation of the head making optimum field of vision possible,

- spatial, segmentary, regional, and global orientation of the spine curvatures,

- geometry and spatial orientation of the sacrum and pelvis,
- geometry and spatial orientation of lower limb joints.

Each parameter has standard values, which were described in the literature based on multiple studies of healthy and ill subjects $[25,26]$.

\section{Regional radiological parameters of sagittal balance \\ Skull}

The skull is the highest located element of the body. According to Dubousset [18], the skull - despite its morphological differences - may be treated as the "cephalic vertebra".

As regards the $\mathrm{X}$-ray diagnostics, to assess the sagittal balance of the skull, parameters described as permanent (not changing after adolescence) will be of help as well as the parameters that are independent of the advancement of the person's life, namely variables whose value depends on the orientation of the skull in the space (Table I), (related to spatial orientation of the head, for which it is natural to aim to have a position ensuring an optimum range of horizontal field of vision and balance).

\section{Cervical spine}

The mobility of the cervical spine is responsible for keeping the head over the body and a horizontal field of vision. The weight of the head is transferred by the occipital condyles of the cranium to the lateral masses, where through joints C1-C2 to C2, dividing the load of C2 to the anterior column (36\% of the load) and $64 \%$ of the load to the posterior column.

A similar course of load is present down to C7 [27]. Large mobility of the cervical section and the compensation mechanisms inside it hinder the definition of unquestionable normative parameters. At present, the selected determined parameters of sagittal balance evaluation of the cervical spine are presented in Figure 2 and Table II.

\section{Sagittal balance parameters}

As regards the papers on spine balance, the greatest advancement in the knowledge was observed in the field of quantitative evaluation methods, standards, and disorders in pelvis biomechanics, the lumbosacral section, and the thoracic section. After a period of studies on the regional parameters of spine assessment, there have been papers describing the inter-regional dependencies, their impact on the pathogenesis of diseases, and the quality of life [28-30].

The key paper was that of Duval-Beaupère et al. [31], describing 3 parameters determining the shape and lo- 
Table I. Radiological permanent parameters and radiological temporary parameters within the skull

\begin{tabular}{|c|c|}
\hline Parameter & Definition \\
\hline COG (centre of gravity) & $\begin{array}{c}\text { The point located on an area of } 1 \mathrm{~cm} 2 \text { situated directly above the external auditory canal } \\
\text { at the height of the nasion-inion line }\end{array}$ \\
\hline Nasion-inion line & $\begin{array}{l}\text { Line that connects indentation between the forehead and the nose and the external occipital } \\
\text { protuberance }\end{array}$ \\
\hline Nasion-opisthion line & $\begin{array}{l}\text { Line that connects indentation between the forehead and the nose and posterior margins } \\
\text { of the foramen magnum (opisthion, this line is parallel to the horizontal semi-circular canal } \\
\text { of the inner ear and reflects the horizontal plane and the ergonomic position of the head) }\end{array}$ \\
\hline McRae's line & Line that connects the anterior and posterior margins of the foramen magnum (basion to opisthion) \\
\hline McGregor's line & Line from the posterosuperior aspect of the hard palate and the caudal aspect of the opisthion \\
\hline \multicolumn{2}{|c|}{ Radiological temporary parameters within the skull } \\
\hline CBVA & An angle measured between lines from the brow and the chin and the vertical \\
\hline McGS & $\begin{array}{c}\text { An angle between the line from the posterosuperior aspect of the hard palate and the caudal aspect } \\
\text { of the opisthion and the horizontal }\end{array}$ \\
\hline
\end{tabular}

CBVA - chin-brow vertical angle, McGS - McGregor's slope.

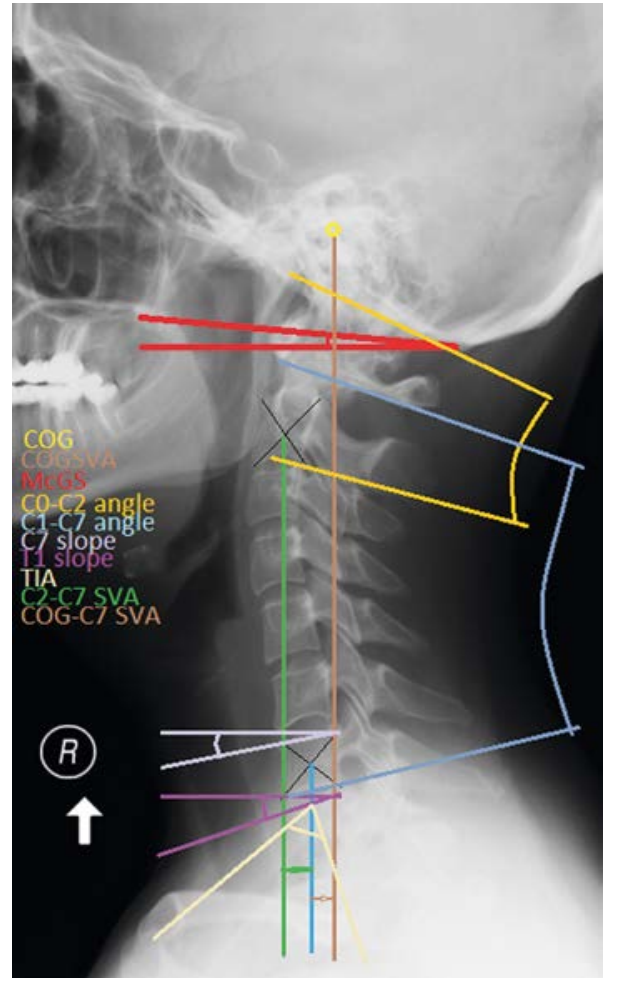

Fig. 2. Selected radiological parameters of the skull and the cervical section.

cation of the pelvis in the sagittal plane and their strict correlation with the parameters of the adjoining lumbar spine. The paper was the basis for the modern understanding of sagittal balance commonly used nowadays in lumbar and thoracic spine surgery.

Treating the pelvis as a solid mass, a permanent parameter was observed, which does not change after adolescence, i.e. pelvic incidence, and variable parameters depending on the location of the pelvis in the sagittal plane pelvic tilt and sacral slope. Inter-regional relations between the pelvis and the sacrum and the lumbar, thoracic section as regards the equilibrium and the course of the sagittal vertical axis (SVA) taken from the body of C7 vertebra were defined as the "sagittal balance of the spine" (Fig. 3, Table III).

\section{Lower limbs}

The spine cannot be treated as an isolated element. The next levels of balance compensation are joints of the lower limbs, such as: hip, knee, and ankle joints. Movement and spatial orientation at particular levels are of particular importance for patients with RA, for whom, during the natural course of the disease, there is an impairment of peripheral joint functioning and the chain of equilibrant forces due to contractures and joint deformation [32, 33].

Impairment in the functioning of peripheral joints limits their role in balance compensation and may result in additional load to the axial joints, including the ill minor joints of the cervical spine. The aim of the paper limits the scope down to the relation between the cervical section and adjoining regions.

\section{Relation between the sagittal balance and the selected parameters of the cervical spine}

Studies on RA focus on the one hand on the aetiology of the disease and identification of the factors predisposing to its advancement, and on the other hand on the improvement of diagnostics, widening the scope of conservative treatment and surgery $[3,6,14]$.

The literature presents a few papers devoted to the sagittal balance in RA. One of them is the paper by Masamoto et al. [34], describing the correlations between the 
Table II. Radiological parameters in the cervical spine

\begin{tabular}{|c|c|}
\hline Parameter & Definition \\
\hline CO-C2 (cobb angle) & This is the angle between the McRae's line and inferior endplate surface of the C2 \\
\hline C1-C2 (cobb angle) & $\begin{array}{l}\text { This is the angle between the line joining the anterior and posterior arches of the atlas and the line } \\
\qquad \text { passing through the lower endplate of C2 }\end{array}$ \\
\hline C1-C7 (cobb angle) & This is the angle between the axis of $\mathrm{C} 1$ and superior endplate of $\mathrm{C} 7$ \\
\hline C7 S (C7 slope) & The angle is formed between a horizontal line and the superior endplate surface of the C7 \\
\hline T1 S (T1 slope) & The angle between the upper endplate of T1 and the horizontal \\
\hline $\begin{array}{l}\text { TIA (thoracic inlet } \\
\text { angle) }\end{array}$ & $\begin{array}{c}\text { The angle formed by a vertical line from the centre of the T1UEP, and a line connecting the centre } \\
\text { of the T1 upper endplate and the upper end of the sternum }\end{array}$ \\
\hline COG-C7 SVA & Distance between vertical line of COG to the vertical line to the centre of C7 \\
\hline C2-C7 SVA & Distance from the posterosuperior corner of $C 7$ to a vertical line from the centre of the $C 2$ vertebra \\
\hline
\end{tabular}

COG - centre of gravity, SVA - sagittal vertical axis, T1UEP - T1 upper endplate.

sagittal balance and other factors affecting the course of RA, such as activity of the disease, bone mineral density, and treatment with glucocorticosteroids.

Other papers by Lee et al. [8] and Mochizuki et al. [35] describe the relation of the selected sagittal balance parameters with the quality of life in RA patients. Cervical spine plays a key role in behaviour and positioning of the head in a way, making assessment of the environment the most favourable; it also transfers the weight related to balance and keeping the head over the body.

This is possible along with the aim to perform one of the basic features and functions of the spine, i.e. efficient balance and concentricity. Keeping the body in a static and dynamic balance in space is possible thanks to compensation mechanisms present in the links of the kinematic chain $[20,36]$.

Cervical spine instability in patients with RA occurs after having used up all the complex compensation mechanisms covering balancing the forces and their moment, in the spine, the pelvis, and the lower limbs. The majority of past papers on balance cover the thoracic and lumbosacral sections and the pelvis [9, 37, 38].

Based on the studies carried out due to other ailments of the spine, it may be observed that the particular regions of the spine and links of the kinematic chain are not independent from one another, and there are multiple significant and close correlations. The parameters that cover the cervical section and show graphically the concentricity of the spine are the sagittal planes from point C2, C7 and from the centre of gravity of the head (COG) [33, 38-40].

Physiologically speaking, the centre of gravity of the head is above the centre of the dens of the C2 body. The course of the COG, SVA, C2SVA, and C7SVA reflects the global and segment balance. In practice, SVA translation may imply clinical consequences. The relation between
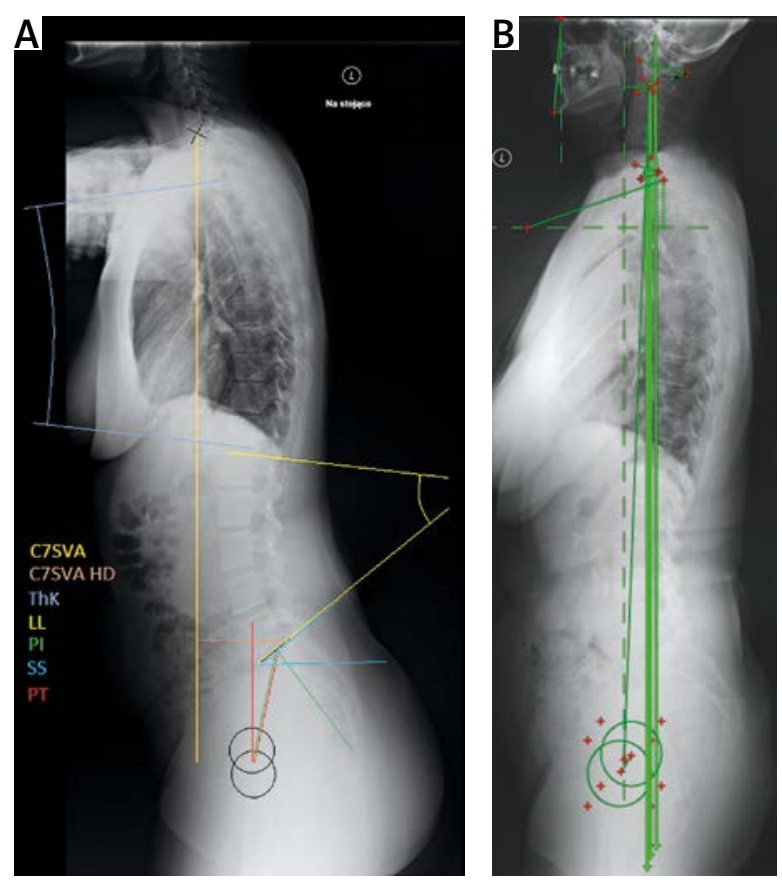

Fig. 3. Selected radiological parameters of the thoracic, lumbar, sacral section and the pelvis (A), selected radiological parameters integrating the cervical, thoracic, lumbar, sacral section, and the pelvis (B).

the dislocation of C2SVA towards C7SVA has been proven along with worsening HRQoL of the patients [41-43].

Another parameter of global balance covering also the cervical section is the odontolit hip axis (OD-HA) [44]. The angle between the line connecting axis dens and the centre of the section connecting the femoral heads and the vertical line going through the centre of the line connecting femoral heads. If the OD-HA is over +2 degrees, or below -5 degrees, the lever arm as regards the force in action is too big and has clinical implications [45, 46]. 
Table III. Basic radiological parameters within the thoracic, lumbar, and sacral section and the pelvis

\begin{tabular}{|c|c|}
\hline Parameter & Definition \\
\hline C7SVA & Sagittal vertical axis of the vertical of C7 (plumb line) \\
\hline C7SVA HD & This is the distance between C7 SVA to the posterior arch of the upper sacral endplate surface \\
\hline ThK & The angle between the superior endplate of the T1 and inferior endplate surface of the T12 \\
\hline LL & Measured between the upper endplate L1 and the upper endplate S1 \\
\hline $\mathrm{PI}$ & $\begin{array}{l}\text { The angle formed between the perpendicular line to the centre point of the superior sacrum endplate surface } \\
\text { and the line connecting the said centre point to the centre of the femur head }\end{array}$ \\
\hline PT & $\begin{array}{l}\text { This is the angle between the upper plumb line from the femur head centre and the centre point of the superior } \\
\text { sacrum endplate surface }\end{array}$ \\
\hline SS & This is the angle between a horizontal line and the slope of the superior sacral endplate surface \\
\hline $\mathrm{OD}-\mathrm{HA}$ & $\begin{array}{l}\text { This is the angle between the vertical and the highest point of the odontoid process (dens) connecting } \\
\text { to the centre of the acetabulum }\end{array}$ \\
\hline
\end{tabular}

C7SVA - C7 sagittal vertical axis, C7SVA HD - horizontal C7 sagittal vertical axis, LL - lumbar lordosis, OD-HA - odontoid hip axis,

PI-pelvic incidence, PT-pelvic tilt, SS - sacral slope, ThK - thorasic kiphosis.

Clinical implications at the level of the relationship between the particular segments of the spine is included in the thoracic inlet tilt concept. Lee et al. [47] presented in their paper the concept of a thoracic inlet tilt as being strictly correlated to the cervical spine balance. The concept was based on a similar one present in the lumbar section.

A relationship between cervical lordosis $(\mathrm{CL})$ and C-Th transition anatomy was observed, similarly to lumbar lordosis (LL) and pelvic anatomy. Th1 starts at the thoracic inlet, the girdle of which also includes the ribs and the upper sternal line. The area is a transition of the movable cervical section into a stiff thoracic spine. $\mathrm{S}=$ The sagittal setting of the cranium and cervical spine may have an impact on upright posture and horizontal field of vision (chin-brow vertical angle - CBVA), similarly to the relationship between the position of the pelvis and the lumbar spine.

Lee et al. [47] and Knott et al. [48] state in their paper a significant relationship between the thoracic inlet angle Tslope and the relocation of the skull and craniovertebral flattening. The position of the skull and the cervical spine is forced by the strive to have a horizontal field of vision, it impacts the compensation global setting of the spine and pelvis. There was a correlation of incidence of pelvis and LL observed while studying the relationship between particular sections of the spine.

Also, correlation has been found as regards $L L$ and thoracic kyphosis as well as thoracic kyphosis and CL. No correlation was observed between the incidence of pelvis and thoracic kyphosis, which complicates the course of the abovementioned kinematic chain of correlations from the pelvis to the cervical spine [12].

This shows that thoracic kyphosis does not result from lumbar lordosis, but rather LL is the result of tho- racic kyphosis and pelvic statics. Likewise, it may be assumed that $C L$ results from the spatial orientation of the skull and thoracic kyphosis. The adjoining stiff thoracic segment and the skull, along with an impaired ligament system of the cervical spine in the course of RA, may particularly foster changes comparable to adjacent segment disease (ASD) $[49,50]$.

A similar phenomenon is observed adjacent to pathologically fused vertebrae and following some spine stabilisation surgeries [51-54]. Compensation disorders also cause the body to be positioned towards the efficiency conus circumference, which results in increased energy used to keep balance; when lasting for a longer time, it results in tiredness, muscle pain, weakness, or in the case of damage to articular surface also joint subluxation and pressure on the adjoining structures. The order of the above-described sequences damaging the ligament system causing CrS, atlanto-axial subluxation, and SAS instability seems not to be random and requires further evaluation

Evaluation of the sagittal balance of the spine is currently one of the basic elements of planning spine disease management, which guarantees improvement in the patients' quality of life. In the case of patients suffering from RA, due to the course of the disease, evaluation of the body balance parameters is of particular importance [55].

While planning the management in the case of patients with features of instability, postural assessment is recommended along with sagittal balance evaluation. The assessment of the cervical spine uses such parameters as CBVA, nasion-inion line, COGSVA, C2SVA, C7SVA, C2-C7 translation, SVA, CL, T slope, transient ischaemic attack, and OD-HA. Postural assessment evaluates whether we are dealing with natural instability or a sec- 
ondary one related to the pathology below the cervical spine.

This impacts the management strategy. In the case of the decision to perform a surgery, this will allow planning of an optimum procedure minimising complications, such as destabilisation and ASD.

\section{Conclusions}

The literature draws too little attention to sagittal balance in patients suffering from RA; however, the importance of surgical procedures in instability of that section before neurological deficits occur is emphasised, as a prevention.

Postural assessment of the spine is the basic element of cervical spine instability in RA diagnostics, as well as a functional test of the cervical spine.

Total assessment of spatial orientation of the skull, cervical spine alignment parameters, and sagittal balance is an important element in planning the surgery of cervical spine instability in RA.

Knowledge on the relation between cervical spine instability in patients suffering from RA, sagittal balance, and the remaining elements of the kinematic chain of the body is still insufficient and requires further studies.

The authors declare no conflict of interest.

\section{References}

1. Canale ST, Beaty JH. Campbel ortopedia operacyjna. Tom II (12 ed.). MediPage, Warszawa 2016: 2019-2022.

2. Nguyen HV, Ludwig SC, Silber J, et al. Rheumatoid arthritis of the cervical spine. Spine J 2004; 4: 329-334, DOI: 10.1016/j. spinee.2003.10.006

3. Gillick JL, Wainwright J, Das K. Rheumatoid arthritis and the cervical spine: a review on the role of surgery. Int J Rheumatol 2015; 2015: 252456, DOI: 10.1155/2015/252456.

4. Mathews JA. Wasting of the small hand muscles in upper and mid-cervical cord lesions. QJM 1998; 91: 691-700, DOI: 10.1093/qjmed/91.10.691.

5. Neva MH, Myllykangas-Luosujärvi R, Kautiainen H, Kauppi M. Mortality associated with cervical spine disorders: a population - based study of 1666 patients with rheumatoid arthritis who died in Finland in 1989. Rheumatology (Oxford) 2001; 40: 123-127, DOI: 10.1093/rheumatology/40.2.123.

6. Cavanilles-Walker JM, Ballestero C, Iborra M, et al. Adult spinal deformity: sagittal imbalance. Intern J Orthopaed 2014; 1: 64-72.

7. Alijani B, Rasoulian J. The sagittal balance of the cervical spine: radiographic analysis of interdependence between the occipitocervical and spinopelvic alignment. Asian Spine J 2020; 14: 287-297, DOI: 10.31616/asj.2019.0165.

8. Lee HS, Lee JS, Shin JK, Goh TS. Correlations between sagittal spinal balance and quality of life in rheumatoid arthri- tis. Clin Spine Surg 2017; 30: E412-E417, DOI: 10.1097/ BSD. 0000000000000246.

9. Glassman SD, Bridwell K, Dimar JR, et al. The impact of positive sagittal balance in adult spinal deformity. Spine (Phila Pa 1976) 2005; 30: 2024-2029, DOI: 10.1097/01.brs.0000179086.30449.96.

10. Schwab F, Patel A, Ungar B, et al. Adult spinal deformity-postoperative standing imbalance: how much can you tolerate? An overview of key parameters in assessing alignment and planning corrective surgery. Spine (Phila Pa 1976) 2010; 35: 2224-2231, DOI: 10.1097/BRS.0b013e3181ee6bd4.

11. Iyer S, Nemani VM, Nguyen J, et al. Impact of cervical sagittal alignment parameters on neck disability. Spine (Phila Pa 1976) 2016; 41: 371-377, DOI: 10.1097/BRS.0000000000001221.

12. Scheer JK, Tang JA, Smith JS, et al. Cervical spine alignment, sagittal deformity, and clinical implications: a review. J Neurosurg Spine 2013; 19: 141-159, DOI: 10.3171/2013.4. SPINE12838.

13. Tanouchi T, Shimizu T, Fueki K, et al. Distal junctional disease after occipitothoracic fusion for rheumatoid cervical disorders: correlation with cervical spine sagittal alignment. Global Spine J 2015; 5: 372-377, DOI: 10.1055/s-0035-1549032.

14. Krauss WE, Bledsoe JM, Clarke MJ, et al. Rheumatoid arthritis of the craniovertebral junction. Neurosurgery 2010; 66 (3 Suppl): 83-95, DOI: 10.1227/01.NEU.0000365854.13997.BO.

15. Mańczak M, Gasik R. Cervical spine instability in the course of rheumatoid arthritis - imaging methods. Reumatologia 2017; 55: 201-207, DOI: 10.5114/reum.2017.69782.

16. Al Khayer A, Sawant N, Emberton P, Sell PJ. Spontaneous odontoid process fracture in rheumatoid arthritis: diagnostic difficulties, pathology and treatment. Injury 2006; 37: 659-662, DOI: 10.1016/j.injury.2005.12.015.

17. Ranawat CS, O'Leary P, Pellicci P, et al. Cervical fusion in rheumatoid arthritis. J Bone Joint Surg Am 1979; 61: 1003-1010.

18. Dubousset J. Three-dimensional analysis of the scoliotic deformity. In: The pediatric spine: principles and practice, Weinstein SL (ed.). Raven Press Ltd., New York 1994: 479-496.

19. Dubousset J. Spinal alignment, balance and harmony throught the ages. Int J Orth 2019; 2: 019-024.

20. Błaszczyk J. Biomechanika kliniczna, podręcznik dla studentów medycyny i fizjoterapii. Wydawnictwo Lekarskie PZWL, Warszawa 2004: 19-23.

21. Toprak CŞ, Duruöz MT, Gündüz OH. Static and dynamic balance disorders in patients with rheumatoid arthritis and relationships with lower extremity function and deformities: a prospective controlled study. Arch Rheumatol 2018; 33: 328-334, DOI: 10.5606/ArchRheumatol.2018.6720.

22. Rome K, Dixon J, Gray M, Woodley R. Evaluation of static and dynamic postural stability in established rheumatoid arthritis: exploratory study. Clin Biomech (Bristol, Avon) 2009; 24: 524-526, DOI: 10.1016/j.clinbiomech.2009.03.005.

23. Le Huec JC, Thompson W, Mohsinaly Y, et al. Sagittal balance of the spine. Eur Spine J 2019; 28: 1889-1905, DOI: 10.1007/ s00586-019-06083-1.

24. Carreon LY, Smith CL, Dimar JR 2nd, Glassman SD. Correlation of cervical sagittal alignment parameters on full-length spine radiographs compared with dedicated cervical radiographs. Scoliosis Spinal Disord 2016; 11: 12, DOI: 10.1186/s13013016-0072-0. 
25. Roussouly P, Pinheiro-Franco J, Labelle H, Gechren M. Sagittal balance of the spine: from normal to pathology: a key for treatment strategy 1st edition, normative values following age and populations. Thieme, New York 2019: 74-79.

26. Hasegawa K, Okamoto M, Hatsushikano S, et al. Normative values of spino-pelvic sagittal alignment, balance, age, and health-related quality of life in a cohort of healthy adult subjects. Eur Spine J 2016; 25: 3675-3686, DOI: 10.1007/s00586016-4702-2.

27. Pal GP, Sherk HH. The vertical stability of the cervical spine. Spine (Phila Pa 1976) 1988; 13: 447-449, DOI: 10.1097/00007632 198805000-00001.

28. During J, Goudfrooij H, Keessen W, et al. Toward standards for posture. Postural characteristics of the lower back system in normal and pathologic conditions. Spine (Phila Pa 1976) 1985; 10: 83-87.

29. Takemitsu Y, Harada Y, Iwahara T, et al. Lumbar degenerative kyphosis. Clinical, radiological and epidemiological studies. Spine (Phila Pa 1976) 1988; 13: 1317-1326.

30. Itoi E. Roentgenographic analysis of posture in spinal osteoporotics. Spine (Phila Pa 1976) 1991; 16: 750-756, DOI: 10.1097/ 00007632-199107000-00011.

31. Duval-Beaupère G, Schmidt C, Cosson P. A Barycentremetric study of the sagittal shape of spine and pelvis: the conditions required for an economic standing position. Ann Biomed Eng 1992; 20: 451-462, DOI: 10.1007/BF02368136.

32. Schmitt Sody M, Kirchhoff C, Buhmann S, et al. Timing of cervical spine stabilisation and outcome in patients with rheumatoid arthritis. Int Orthop 2008; 32: 511-516, DOI: 10.1007/ s00264-007-0349-2.

33. Ferrero E, Liabaud B, Challier V. et al. Role of pelvic translation and lower-extremity compensation to maintain gravity line position in spinal deformity. J Neurosurg Spine 2016; 24: 436-446, DOI: 10.3171/2015.5.SPINE14989.

34. Masamoto K, Otsuki B, Fujibayashi S, et al. Factors influencing spinal sagittal balance, bone mineral density, and Oswestry Disability Index outcome measures in patients with rheumatoid arthritis. Eur Spine J 2018; 27: 406-415, DOI: 10.1007/ s00586-017-5401-3.

35. Mochizuki T, Yano K, Shirahata T, et al. Spinal sagittal balance associated with age, vertebral fracture, and functional disability in patients with rheumatoid arthritis: a cross-sectionl study. Mod Rheumatol 2020; 1002-1008, DOI:10.1080/14397595. 2019.1702247

36. Barrey C, Roussouly P, Le Huec JC, et al. Compensatory mechanisms contributing to keep the sagittal balance of the spine. Eur Spine J 2013; 22 Suppl 6: S834-S841, DOI: 10.1007/s00586013-3030-z

37. Bridwell $\mathrm{KH}$, Baldus C, Berven S, et al. Changes in radiographic and clinical outcomes with primary treatment adult spinal deformity surgeries from two years to three- to five-years follow-up. Spine (Phila Pa 1976) 2010; 35: 1849-1854, DOI: 10.1097/BRS.0b013e3181efa06a.

38. Schwab F, Farcy JP, Bridwell K, et al. A clinical impact classification of scoliosis in the adult. Spine (Phila Pa 1976) 2006; 31 2109-2114, DOI: 10.1097/01.brs.0000231725.38943.ab.

39. Jackson RP, McManus AC. Radiographic analysis of sag-ittal plane alignment and balance in standing volunteers and patients with low back pain matched for age, sex, and size. A prospective controlled clinical study. Spine (Phila Pa 1976) 1994; 19: 1611-1618, DOI: 10.1097/00007632-19940700100010.

40. Beier G, Schuck M, Schuller E, Spann W (eds.). Determination of physical data of the Head I. Center of Gravity and Moments of Inertia of Human Heads. Institute of Forensic Medicine, University of Munich, Munich 1979: 44

41. Tang JA, Scheer JK, Smith JS, et al. The impact of standing regional cervical sagittal alignment on outcomes in posterior cervical fusion surgery. Neurosurgery 2012; 71: 662-669; discussion 669, DOI: 10.1227/NEU.0b013e31826100c9.

42. Yuan W, Zhu Y, Zhu H, et al. Preoperative cervical sagittal alignment parameters and their impacts on myelopathy in patients with cervical spondylotic myelopathy: a retrospective study. Peer J 2017; 5: e4027, DOI: 10.7717/peerj.4027.

43. Mac-Thiong JM, Transfeldt EE, Mehbod AA, et al. Can c7 plumbline and gravity line predict health related quality of life in adult scoliosis? Spine (Phila Pa 1976) 2009; 34: E519-E527, DOI: 10.1097/ BRS.0b013e3181a9c7ad.

44. Amabile $\mathrm{C}$, Pillet $\mathrm{H}$, Lafage $\mathrm{V}$, et al. A new quasi-invariant parameter characterizing the postural alignment of young asymptomatic adults. Eur Spine J 2016; 25: 3666-3674, DOI: 10.1007/s00586-016-4552-y.

45. Faundez AA, Richards J, Maxy P, et al. The mechanism in junctional failure of thoraco-lumbar fusions. Part II: analysis of a series of PJK after thoraco-lumbar fusion to determine parameters allowing to predict the risk of junctional breakdown. Eur Spine J 2018; 27 (Suppl 1): 139-148, DOI: 10.1007/s00586-017-5426-7.

46. Berjano P, Cecchinato R, Damilano M, et al. Preoperative calculation of the necessary correction in sagittal imbalance surgery: validation of three predictive methods. Eur Spine J 2013; 22 Suppl 6: S847-S852, DOI: 10.1007/s00586-013-3025-9.

47. Lee SH, Kim KT, Seo EM, et al. The influence of thoracic inlet alignment on the craniocervical sagittal balance in asymptomatic adults. J Spinal Disord Tech 2012; 25: E41-E47, DOI: 10.1097/BSD.0b013e3182396301.

48. Knott PT, Mardjetko SM, Techy F. The use of the T1 sagittal angle in predicting overall sagittal balance of the spine. Spine J 2010; 10: 994-998, DOI: 10.1016/j.spinee.2010.08.031.

49. Hilibrand AS, Robbins M. Adjacent segment degeneration and adjacent segment disease: the consequences of spinal fusion? Spine J 2004; 4 (6 Suppl): 190S-194S, DOI: 10.1016/j. spinee.2004.07.007.

50. Eck JC, Humphreys SC, Lim TH, et al. Biomechanical study on the effect of cervical spine fusion on adjacent-level intradiscal pressure and segmental motion. Spine (Phila Pa 1976) 2002; 27: 2431-2434, DOI: 10.1097/00007632-200211150-00003.

51. Rihn JA, Lawrence J, Gates C, et al. Adjacent segment disease after cervical spine fusion. Instr Course Lect 2009; 58: 747-756.

52. Seo $M$, Choi D. Adjacent segment disease after fusion for cervical spondylosis; myth or reality? Br J Neurosurg 2008; 22: 195-199, DOI: 10.1080/02688690701790605.

53. Katsuura A, Hukuda S, Saruhashi Y, Mori K. Kyphotic malalignment after anterior cervical fusion is one of the factors promoting the degenerative process in adjacent interver- 
tebral levels. Eur Spine J 2001; 10: 320-324, DOI: 10.1007/ s005860000243.

54. Ito $\mathrm{H}$, Neo M, Sakamoto T, et al. Subaxial subluxation after atlantoaxial transarticular screw fixation in rheumatoid patients. Eur Spine J 2009; 18: 869-876, DOI: 10.1007/s00586009-0945-5.
55. Schmitt-Sody M, Kirchhoff C, Buhmann S, et al. Timing of cervical spine stabilisation and outcome in patients with rheumatoid arthritis. Int Orthop 2008; 32: 511-516, DOI: 10.1007/ s00264-007-0349-2. 